\title{
Updated Meta-analysis on the Closure of Patent Foramen Ovale in Reduction of Stroke Rates: the DEFENSE-PFO Trial Does not Change the Scenario
}

\author{
Michel Pompeu Barros Oliveira Sá 1,2,3, MD, MSc, PhD; Erik Everton Silva Vieira ${ }^{1,2,4}$, MD; Luiz Rafael Pereira Cavalcanti ${ }^{1,2}$, \\ MD; Roberto Gouveia Silva Diniz ${ }^{1,2}$, MD; Sérgio da Costa Rayol ${ }^{1,2}$, MD; Alexandre Motta de Menezes $^{1,2}$, MD; Ricardo \\ Felipe de Albuquerque Lins ${ }^{1,2}$, MD; Ricardo Carvalho Lima ${ }^{1,2,3,4}$, MD, MSc, PhD, ChM, AATS
}

\begin{abstract}
Objective: We aimed to analyze whether patent foramen ovale (PFO) closure reduces the risk of stroke, assessing also some safety outcomes after the publication of a new trial.

Introduction: The clinical benefit of closing a PFO has been an open question, so it is necessary to review the current state of published medical data in regards to this subject.

Methods: MEDLINE, EMBASE, CENTRAL/CCTR, SCiELO, LILACS, Google Scholar and reference lists of relevant articles were used to search for randomized controlled trials (RCTs) that reported any of the following outcomes: stroke, death, major bleeding or atrial fibrillation. Six studies fulfilled our eligibility criteria and included 3560 patients (1889 for PFO closure and 1671 for medical therapy.

Results: The risk ration (RR) for stroke in the "closure" group compared with the "medical therapy" showed a statistically
\end{abstract}

significant difference between the groups, favouring the "closure" group (RR $0.366 ; 95 \% \mathrm{Cl} 0.171-0.782, P=0.010$ ). There was no statistically significant difference between the groups regarding the safety outcomes, death and major bleeding, but we observed an increase in the risk of atrial fibrillation in the "closure" group (RR 4.131; 95\%Cl 2.293-7.443, $P<0.001$ ). We also observed that the larger the proportion of effective closure, the lower the risk of stroke.

Conclusion: This meta-analysis found that stroke rates are lower with percutaneously implanted device closure than with medical therapy alone, being these rates modulated by the rates of hypertension, atrial septal aneurysm and effective closure. The publication of a new trial did not change the scenario in the medical literature.

Keywords: Foramen Ovale, Patent. Vascular Closure Devices. Meta-analysis.

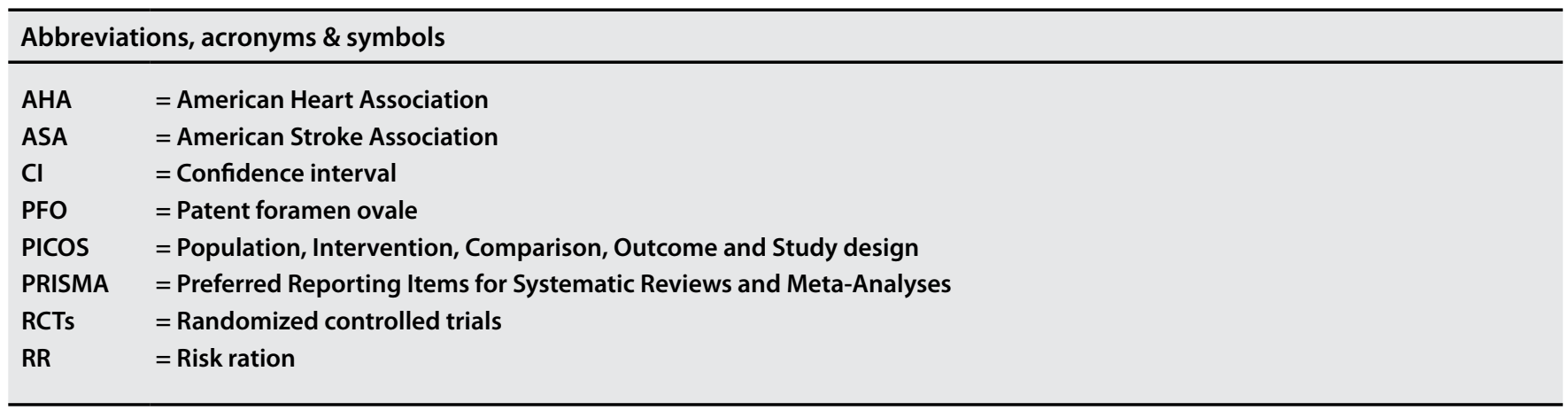

'Department of Cardiovascular Surgery of the Pronto Socorro Cardiológico de Pernambuco (PROCAPE), Recife, PE, Brazil.

${ }^{2}$ Universidade de Pernambuco (UPE), Recife, PE, Brazil.

${ }^{3}$ Nucleus of Postgraduate Studies and Research in Health Sciences of the Faculdade de Ciências Médicas and Instituto de Ciências Biológicas (FCM/ICB), Recife, PE, Brazil.

${ }^{4}$ The CASUAL Investigators - CArdiovascular SUgery Academic League of the Universidade de Pernambuco (UPE), Recife, PE, Brazil.
No financial support.

No conflict of interest

Correspondence Address:

Michel Pompeu Barros Oliveira Sá

Pronto-Socorro Cardiológico de Pernambuco (PROCAPE)

Rua dos Palmares S/N - Santo Amaro - Recife, PE, Brazil - Zip code: 74970-240

E-mail: michel_pompeu@yahoo.com.br 


\section{INTRODUCTION}

\section{Rationale}

Current American Heart Association;American Stroke Association (AHA;ASA) guidelines do not support the use of patent foramen ovale (PFO) closure among patients with PFO and cryptogenic stroke ${ }^{[1]}$. However, new meta-analysis of randomized controlled trials (RTCS)with the same number of patients and studies were published ${ }^{[2-12]}$ this year, all of them coming to the same conclusion: stroke rates are lower with percutaneously implanted device closure than with medical therapy alone. As we know, the medical literature currently changes at a fast pace. No sooner had all these meta-analyses been published than a new trial (DEFENSEPFO) came out. Therefore, it is necessary to constantly review the current published medical data with regard to this subject.

\section{Objective}

We aimed to analyze whether PFO closure reduces the risk of stroke, assessing also some safety outcomes. This analysis was planned in accordance with current guidelines for performing comprehensive systematic reviews and meta-analysis with meta-regression, including the Preferred Reporting Items for Systematic Reviews and Meta-Analyses (PRISMA) ${ }^{[13]}$ guidelines for RCTs. We pre-specified our analytical plan and registered the study protocol with PROSPERO, the international prospective register of systematic reviews (CRD42018084583).

\section{METHODS}

\section{Eligibility Criteria}

With the Population, Intervention, Comparison, Outcome and Study desing (PICOS) strategy, studies were only considered if: 1) the population comprised patients with recent stroke or transient ischemic attack who had a PFO; 2) there was an intervention group of device closure; 3 ) there was a control group receiving medical therapy; 4) studied outcomes included any of the following: stroke, death, major bleeding, atrial fibrillation; 5) studies were RCTs.

\section{Information Sources}

The following databases were used (until April 2018): MEDLINE; EMBASE; CENTRAL/CCTR (Cochrane Controlled Trials Register); ClinicalTrials.gov; SciELO (Scientific Electronic Library Online); LILACS (Literatura Latino Americana em Ciências da Saúde); Google Scholar; and reference lists of relevant articles.

\section{Search}

We conducted the research with Medical Subject Headings (MeSH) terms ('Foramen Ovale, Patent' OR 'Patent Oval Foramen' OR'Oval Foramen, Patent' OR 'Patent Foramen Ovale') AND ('Stroke' OR 'Cerebrovascular Accident' OR 'Cerebrovascular Accidents' OR 'CVA' OR 'CVAs' OR 'Cerebrovascular Apoplexy' OR 'Apoplexy, Cerebrovascular' OR 'Vascular Accident, Brain' OR 'Brain Vascular Accident ' OR 'Brain Vascular Accidents' OR 'Vascular Accidents, Brain ' OR 'Cerebrovascular Stroke' OR 'Cerebrovascular Strokes' OR 'Stroke, Cerebrovascular'OR'Strokes, Cerebrovascular'OR'Apoplexy
' OR 'Cerebral Stroke' OR 'Cerebral Strokes' OR 'Stroke, Cerebral' OR 'Strokes, Cerebral' OR 'Stroke, Acute' OR 'Acute Stroke' OR 'Acute Strokes' OR 'Strokes, Acute' OR 'Cerebrovascular Accident, Acute' OR 'Acute Cerebrovascular Accident' OR 'Acute Cerebrovascular Accidents' OR 'Cerebrovascular Accidents, Acute').

\section{Study Selection}

The following steps were taken: 1) identification of titles of records through database research; 2) removal of duplicates; 3) screening and selection of abstracts; 4) assessment for eligibility through full-text articles; and 5) final inclusion in the study. One reviewer followed steps 1 to 3. Two independent reviewers followed step 4 and selected studies. The inclusion or exclusion of studies was decided unanimously. When there was disagreement, a third reviewer made the final decision.

\section{Data Items}

The crude endpoints were stroke, death (any cause), major bleeding and atrial fibrillation.

\section{Data Collection Process}

Two independent reviewers extracted the data. When there was disagreement about data, a third reviewer checked the data and made the final decision. From each study, we extracted patient characteristics, study design and outcomes.

\section{Risk of Bias in Individual Studies}

Included studies were assessed for the following characteristics: sequence generation (randomization); allocation concealment (selection bias); blinding of participants and personnel (performance bias); blinding of outcome assessors (detection bias); incomplete outcome data addressed (attrition bias) and selective outcome reporting (reporting bias). Taking these characteristics into account, the papers were classified into A (low risk of bias), B (moderate risk of bias) or C (high risk of bias). Two independent reviewers assessed risk of bias. Agreement between the two reviewers was assessed with Kappa statistics for full-text screening and rating of relevance and risk of bias. When there was disagreement on risk of bias, a third reviewer checked the data and made the final decision.

\section{Summary Measures}

The principal summary measures were RR with 95\% confidence interval $(\mathrm{Cl})$ and $P$ values (considered statistically significant when $P<0.05)$ for stroke, death, major bleeding and atrial fibrillation. The meta-analysis was completed with the Comprehensive MetaAnalysis software (version 2, Biostat, Inc., Englewood, NJ, USA).

\section{Synthesis of Results}

Forest plots were generated for graphical presentations of clinical outcomes, and we performed the $\mathrm{I}^{2}$ test and $x^{2}$ test for the assessment of heterogeneity across the studies ${ }^{[14]}$. Interstudy heterogeneity was explored using the $x^{2}$ statistic, but the $\mathrm{I}^{2}$-value was calculated to quantify the degree of heterogeneity 
across the studies that could not be attributable to chance alone. When $\mathrm{I}^{2}$ was more than $50 \%$, significant statistical heterogeneity was considered to be present. Each study was summarized by the difference in means or RR, depending on the analyzed outcome. The RR and the differences in means were combined across studies using a weighted DerSimonian-Laird random effects model ${ }^{[15]}$.

\section{Risk of Bias Across Studies}

To assess publication bias, a funnel plot was generated for each outcome, statistically assessed by Begg and Mazumdar's test $^{[16]}$ and Egger's test ${ }^{[17]}$.

\section{Sensitivity Analysis}

We analyzed the pool data regarding the outcome "stroke" according to the presence (or absence) of atrial septal aneurysm.

\section{Meta-Regression Analysis}

Meta-regression analysis was performed to determine whether the effects of the PFO closure were modulated by prespecified factors. Meta-regression graphs describe the effect of aspirin on the outcome (plotted on the $y$-axis) as a function of a given factor (plotted as a mean or proportion of that factor on the $x$-axis). Meta-regression coefficients show the estimated increase in log risk ration (RR) per unit increase in the covariate. Since log $\mathrm{RR}>0$ corresponds to $\mathrm{RR}>1$ and $\log \mathrm{RR}<0$ corresponds to $\mathrm{RR}$ $<1$, a negative coefficient would indicate that as a given factor increases, the RR decreases, and vice versa.

The pre-determined modulating factors examined were: age (mean - years), male gender (\%), hypertension (\%), smoking (\%), large shunt before the interventions, atrial septal aneurysm and effective closure (freedom from large shunt after the interventions).

\section{RESULTS}

\section{Study Selection}

A total of 3,970 citations were identified, of which 10 studies were potentially relevant and retrieved as full-text. Six ${ }^{[18-23]}$ publications fulfilled our eligibility criteria. Interobserver reliability of study relevance was excellent (Kappa=0.82). Agreement for decisions related to study validity was very good (Kappa=0.84). The search strategy can be seen in Figure 1.
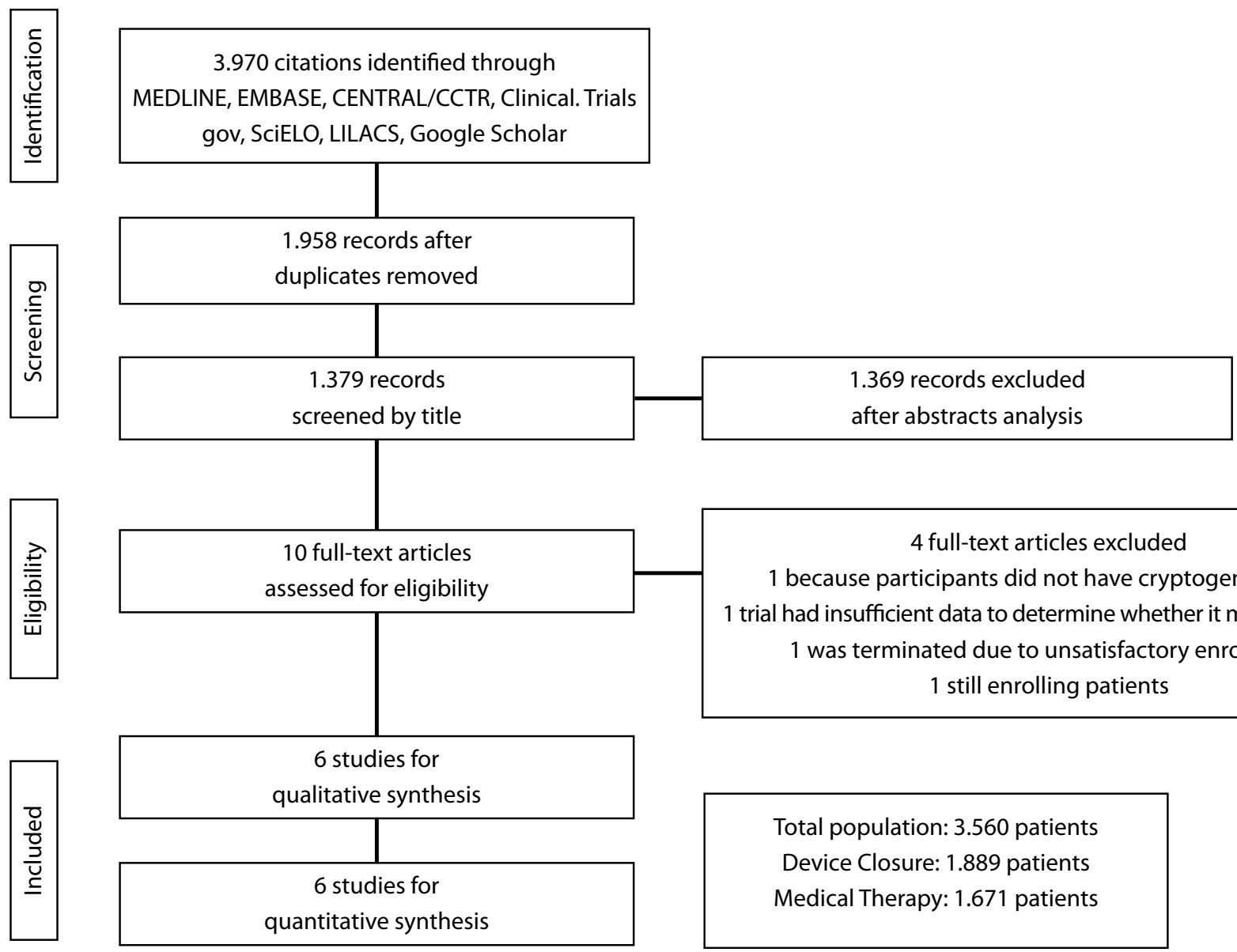

4 full-text articles excluded

1 because participants did not have cryptogenic stroke 1 trial had insufficient data to determine whether it met the criteria 1 was terminated due to unsatisfactory enroliment 1 still enrolling patients

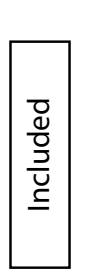

Fig. 1 - Flow Diagram of Studies Included in Data Search.

CCTR=Cochrane Controlled Trials Register; LILACS=Literatura Latino Americana em Ciências da Saúde; SciELO=Scientific Electronic Library Online 


\section{Study Characteristics}

A total of 3,560 patients (device closure: 1,889 patients; medical therapy: 1,671 patients) were included from studies published from 2012 to 2018. All the trials were multicentric. Most studies consisted of patients whose mean or median age was approximately on the fourth decade of life. The medical therapy in the studies was not homogeneous, since different regimens were applied (aspirin, clopidogrel, dipyridamole, combined regimens, etc). The same goes for the devices used, being the CLOSE trial most noteworthy for applying various devices (Table 1). The overall internal validity was considered "low risk of bias" (Table 2).

\section{Synthesis of Results}

The RR for stroke in the "device closure" group compared with the "medical therapy" group in each study is reported in Figure 2.
There was evidence of moderate heterogeneity of treatment effect among the studies for stroke. The overall RR $(95 \% \mathrm{Cl})$ of stroke showed a statistically significant difference between the groups, favouring the "device closure" group (random effect model: RR $0.366 ; 95 \% \mathrm{Cl} 0.171-0.782, P=0.010)$.

The RR for death in the "device closure" group compared with the "medical therapy" group in each study is reported in Figure $3 \mathrm{~A}$. There was no evidence of heterogeneity of treatment effect among the studies for death. The overall RR $(95 \% \mathrm{Cl})$ of death showed no statistically significant difference between the groups (random effect model: RR 0.781; 95\% Cl $0.331-1.843, P=0.572$ ).

The RR for major bleeding in the "device closure" group compared with the "medical therapy" group in each study is reported in Figure 3B. There was evidence of mild heterogeneity of treatment effect among the studies for major bleeding. The overall RR $(95 \% \mathrm{Cl})$ of major bleeding showed no statistically

Table 1. Characteristics of populations.

\begin{tabular}{|c|c|c|c|c|c|c|}
\hline & $\begin{array}{l}\text { DEFENSE-PFO } \\
(\mathrm{N}=120)\end{array}$ & $\begin{array}{c}\text { CLOSE } \\
(\mathrm{N}=473)\end{array}$ & $\begin{array}{l}\text { REDUCE } \\
(\mathrm{N}=664)\end{array}$ & $\begin{array}{c}P C \\
(N=414)\end{array}$ & $\begin{array}{l}\text { RESPECT } \\
(\mathrm{N}=980)\end{array}$ & $\begin{array}{r}\text { CLOSURE } \\
(\mathrm{N}=909)\end{array}$ \\
\hline$\%$ of data in meta-analysis & 3.3 & 13.3 & 18.7 & 11.6 & 27.5 & 25.5 \\
\hline \multicolumn{7}{|l|}{ Demographic variables } \\
\hline Age $\pm S D$, years & $49.0 \pm 15.0$ & $43.3 \pm 10.3$ & $45.1 \pm 9.45$ & $44.5 \pm 10.2$ & $45.4 \pm 9.8$ & $45.5 \pm 10.2$ \\
\hline Male (\%) & 55.8 & 58.9 & 60.1 & 49.8 & 54.7 & 51.8 \\
\hline \multicolumn{7}{|l|}{ Medical history variables } \\
\hline Currently smoking (\%) & 21.7 & 28.9 & 13.3 & 23.9 & 13.3 & 15.2 \\
\hline Coronary artery disease (\%) & NR & NR & NR & 1.9 & 2.9 & 2.1 \\
\hline Diabetes (\%) & 11.7 & 2.5 & 4.2 & 2.6 & 7.4 & 7.8 \\
\hline Hypercholesterolemia (\%) & 35.8 & 13.9 & NR & 27.1 & 39.5 & 44.1 \\
\hline Hypertension (\%) & 32.5 & 10.7 & 25.6 & 25.8 & 31.4 & 31.0 \\
\hline Migraine (\%) & NR & 30.6 & NR & 20.5 & 38.8 & 33.6 \\
\hline Prior stroke/TIA (\%) & NR & 3.6 & 85 & 37.4 & 18.6 & 12.5 \\
\hline \multicolumn{7}{|l|}{ Echocardiographic variables } \\
\hline Atrial septal aneurysm (\%) & 10.8 & 32.7 & NR & 23.7 & 35.6 & 35.6 \\
\hline Large shunt (\%) & 57.5 & 92.8 & 39.3 & 21.7 & 76.1 & 61.1 \\
\hline \multicolumn{7}{|l|}{ Treatment variables } \\
\hline Randomized to device closure (\%) & 50.0 & 50.3 & 66.4 & 49.3 & 50.9 & 49.2 \\
\hline Treated with medical therapy (\%) & 50.0 & 49.6 & 33.6 & 80.0 & 88.0 & 84.7 \\
\hline Device & $\begin{array}{c}\text { Amplatzer PFO } \\
\text { Occluder (St. } \\
\text { Jude Medical) }\end{array}$ & $\begin{array}{c}\text { Amplatzer PFO } \\
\text { Occluder or } \\
\text { Cribriform; Starflex; } \\
\text { CardioSeal; Intrasept } \\
\text { PFO; PFOStar; Helex; } \\
\text { Premere; PFO occluder } \\
\text { OCCLUTECH; PFO } \\
\text { occluder GORE (GSO) }\end{array}$ & $\begin{array}{c}\text { EITHER } \\
\text { the Helex } \\
\text { Septal Occluder } \\
\text { device OR the } \\
\text { Cardioform } \\
\text { Septal Occluder }\end{array}$ & $\begin{array}{c}\text { Amplatzer PFO } \\
\text { Occluder (St. } \\
\text { Jude Medical) }\end{array}$ & $\begin{array}{c}\text { Amplatzer PFO } \\
\text { Occluder (disc } \\
\text { occluder) }\end{array}$ & $\begin{array}{c}\text { STARFlex } \\
\text { septal } \\
\text { closure } \\
\text { system } \\
\text { (umbrella } \\
\text { occluder) }\end{array}$ \\
\hline
\end{tabular}


Table 2. Analysis of Risk of Bias: Internal Validity.

\begin{tabular}{l|c|c|c|c|c|c}
\hline Study & Randomization & Selection bias & $\begin{array}{c}\text { Performance } \\
\text { bias }\end{array}$ & $\begin{array}{c}\text { Detection } \\
\text { bias }\end{array}$ & $\begin{array}{c}\text { Attrition } \\
\text { bias }\end{array}$ & $\begin{array}{c}\text { Reporting } \\
\text { bias }\end{array}$ \\
\hline DEFENSE-PFO & $\mathrm{A}$ & $\mathrm{B}$ & $\mathrm{B}$ & $\mathrm{A}$ & $\mathrm{A}$ & $\mathrm{A}$ \\
\hline CLOSE 2017 & $\mathrm{~A}$ & $\mathrm{~A}$ & $\mathrm{~B}$ & $\mathrm{~A}$ & $\mathrm{~A}$ & $\mathrm{~A}$ \\
\hline REDUCE 2017 & $\mathrm{~A}$ & $\mathrm{~A}$ & $\mathrm{~B}$ & $\mathrm{~A}$ & $\mathrm{~A}$ & $\mathrm{~A}$ \\
\hline RESPECT 2013 & $\mathrm{A}$ & $\mathrm{A}$ & $\mathrm{A}$ & $\mathrm{A}$ & $\mathrm{A}$ & $\mathrm{A}$ \\
\hline PC 2013 & $\mathrm{A}$ & $\mathrm{A}$ & $\mathrm{A}$ & $\mathrm{A}$ & $\mathrm{A}$ & $\mathrm{A}$ \\
\hline CLOSUREI2012 & $\mathrm{A}$ & $\mathrm{A}$ & $\mathrm{A}$ & $\mathrm{A}$ & $\mathrm{A}$ & $\mathrm{A}$ \\
\hline
\end{tabular}

$A=$ risk of bias is low; $B=$ risk of bias is moderate; $C=$ risk of bias is high; $D=$ incomplete reporting

\section{Stroke}

\begin{tabular}{lrlllrr} 
Study name & \multicolumn{4}{c}{ Statistics for each study } & Weight (R \\
& $\begin{array}{r}\text { Risk } \\
\text { ratio }\end{array}$ & $\begin{array}{c}\text { Lower } \\
\text { limit }\end{array}$ & $\begin{array}{c}\text { Upper } \\
\text { limit }\end{array}$ & $\begin{array}{r}\text { P-Value } \\
\text { Relative } \\
\text { weight }\end{array}$ \\
DEFENSE-PFO 2018 & 0.091 & 0.005 & 1.609 & 0.102 & 5.94 \\
CLOSE 2017 & 0.034 & 0.002 & 0.568 & 0.019 & 6.15 \\
REDUCE 2017 & 0.253 & 0.096 & 0.665 & 0.005 & 23.81 \\
RESPECT 2013 & 0.542 & 0.242 & 1.215 & 0.137 & 26.95 \\
PC 2013 & 0.206 & 0.024 & 1.747 & 0.147 & 9.54 \\
CLOSURE 1 2012 & 0.954 & 0.440 & 2.068 & 0.905 & 27.62 \\
Overall effect & 0.366 & 0.171 & 0.782 & 0.010 &
\end{tabular}

Total (95\% Cl): 1889 (Device Closure); 1671 (Medical Therapy)

Total events: 28 (Device Closure); 65 (Medical Therapy)

Test for heterogeneity: $\mathrm{Chi}^{2}=10.09 ; \mathrm{df}=5(\mathrm{P}=0.073) ; \mathrm{I}^{2}=50.4 \%$

Test for overall random effect: $Z=-2.59(P=0.010)$

Fig. 2 - Forest Plots of Efficacy Outcomes.

significant difference between the groups (random effect model: RR 0.878 ; $95 \%$ Cl $0.446-1.727, P=0.706)$.

The RR for atrial fibrillation in the "device closure" group compared with the "medical therapy" group in each study is reported in Figure 3C. There was evidence of mild heterogeneity of treatment effect among the studies for atrial fibrillation. The overall RR $(95 \% \mathrm{Cl})$ of atrial fibrillation showed a statistically significant difference between the groups (random effect model: RR $4.131 ; 95 \% \mathrm{Cl} 2.293-7.443, P<0.001)$.

\section{Risk of Bias Across Studies}

Funnel plot analysis (Figure 4) disclosed no asymmetry around the axis for the outcomes stroke, major bleeding and atrial fibrillation, which means that we have low risk of publication bias related to these outcomes. However, we detected a possibility of publication bias for the outcome death.

\section{Sensitivity Analysis}

Searching for evidence of a particular impact of the presence of an atrial septal aneurysm on the results, we detected no difference between the groups (Figure 5). Unfortunately, the REDUCE tria[ [20] was left out of this last analysis because the presence of an atrial septal aneurysm was determined at the time of the PFO closure procedure and, therefore, it was not recorded before trial entry or among the patients in the antiplatelet-only group.

\section{Meta-Regression Analysis}

Meta-regression coefficients were statistically significant for the variables hypertension, atrial septal aneurysm and effective closure regarding the outcome "stroke". For the variables hypertension and atrial septal aneurysm, we observed that the larger the proportion of patients with hypertension and the larger the proportion of 
A)

Study name

DEFENSE-PFO 2018

CLOSE 2017

REDUCE 2017

RESPECT 2013

PC 2013

CLOSURE I 2012

Overall effect

Total (95\% Cl): 1889 (Device Closure); 1671 (Medical Therapy)

Total events: 9 (Device Closure); 10 (Medical Therapy)

Test for heterogeneity: $\left.C h\right|^{2}=2.823 ; \mathrm{df}=5(P=0.727) ; \mathrm{l}^{2}=0.0 \%$

Test for overall random effect: $Z=-0.56(P=0.572)$

\section{Death}

Weight (Random)

Relative

weight

9.77

9.65

8.03

$\begin{array}{lllll}0.482 & 0.121 & 1.916 & 0.300 & 38.75\end{array}$

$\begin{array}{llll}5.146 & 0.249106 .544 & 0.289 & 8.04\end{array}$

$\begin{array}{lllll}0.517 & 0.095 & 2.807 & 0.445 & 25.77\end{array}$

(\%)

5.77

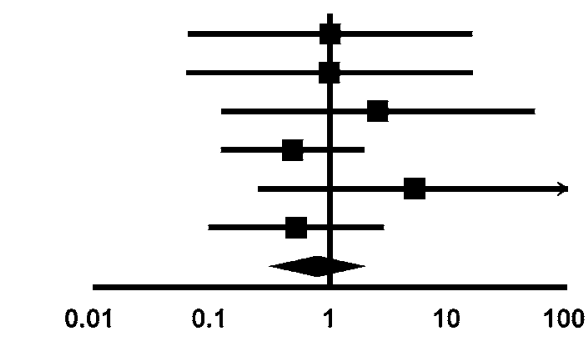

Favours Device Closure Favours Medical Therapy

B)

\section{Major bleeding}

Study name

DEFENSE-PFO 2018

CLOSE 2017

REDUCE 2017

RESPECT 2013

PC 2013

CLOSURE I 2012

Overall effect

Total (95\% Cl): 1889 (Device Closure); 1671 (Medical Therapy)

Total events: 30 (Device Closure); 29 (Medical Therapy)

Test for heterogeneity: $\mathrm{ChI}^{2}=6.98 ; \mathrm{df}=5(\mathrm{P}=0.222) ; \mathrm{I}^{2}=28.3 \%$

Test for overall random effect: $Z=-0.38(P=0.706)$
Weight (Random)

Relative

weight

$\begin{array}{lllll}0.200 & 0.010 & 4.080 & 0.296 & 4.65\end{array}$

$\begin{array}{lllll}0.395 & 0.077 & 2.016 & 0.264 & 13.45\end{array}$

$\begin{array}{lllll}0.674 & 0.237 & 1.919 & 0.460 & 24.88\end{array}$

$\begin{array}{lll}4.820 & 0.232100 .139 & 0.310\end{array}$

4.60

30.34

22.08

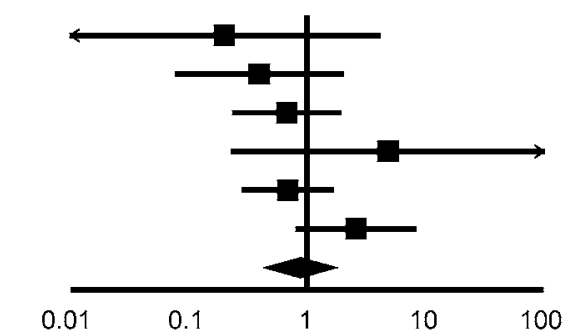

Favours Device Closure Favours Medical Therapy

C)

\begin{tabular}{|c|c|c|c|c|c|c|}
\hline \multirow[t]{2}{*}{ Study name } & \multicolumn{4}{|c|}{ Statistics for each study } & \multicolumn{2}{|c|}{ Weight (Random) } \\
\hline & $\begin{array}{l}\text { Risk } \\
\text { ratio }\end{array}$ & $\begin{array}{c}\text { Lower } \\
\text { limit }\end{array}$ & $\begin{array}{l}\text { Upper } \\
\text { limit }\end{array}$ & P-Value & $\begin{array}{c}\text { Relative } \\
\text { weight }\end{array}$ & $(\%)$ \\
\hline DEFENSE-PFO 2018 & 5.000 & 0.2451 & 102.002 & 0.296 & 3.76 & \\
\hline CLOSE 2017 & 5.431 & 1.217 & 24.237 & 0.027 & 14.65 & \\
\hline REDUCE 2017 & 14.664 & 2.0111 & 106.952 & 0.008 & 8.50 & \\
\hline RESPECT 2013 & 2.066 & 0.850 & 5.022 & 0.110 & 37.78 & \\
\hline PC 2013 & 3.088 & 0.631 & 15.124 & 0.164 & 13.07 & \\
\hline CLOSURE I 2012 & 7.924 & 2.396 & 26.205 & 0.001 & 22.24 & \\
\hline Overall effect & 4.131 & 2.293 & 7.443 & $<0.001$ & & \\
\hline
\end{tabular}

\section{Atrial fibrillation}

Weight (Random)

)

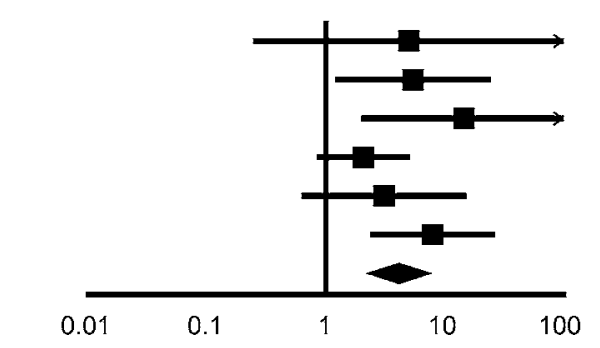

Favours Device Closure Favours Medical Therapy

Fig. 3 - Forest Plots of Safety Outcomes. 


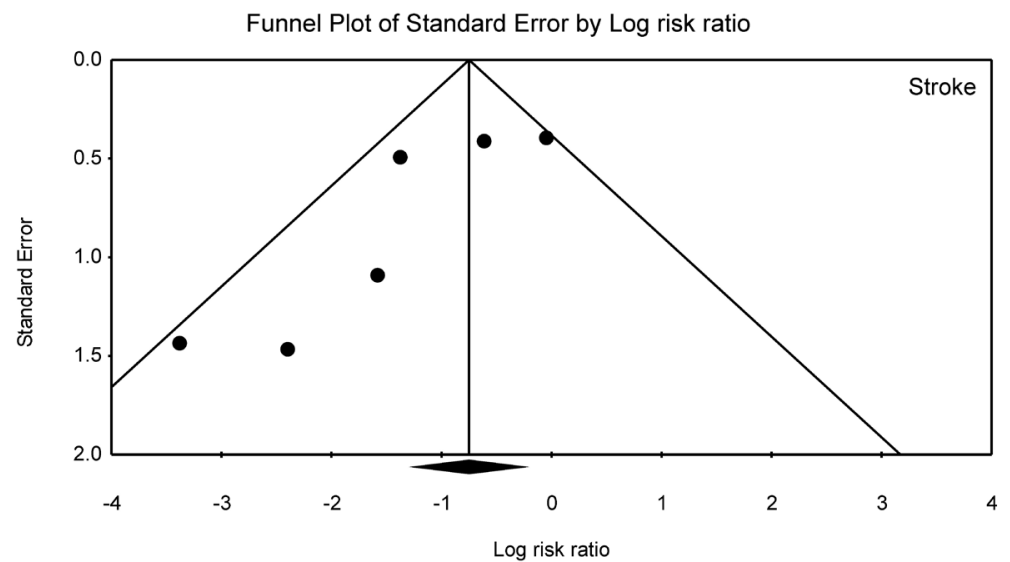

Begg and Mazumdar's test (P-value): 0.132 Egger's test (P-value): 0.053

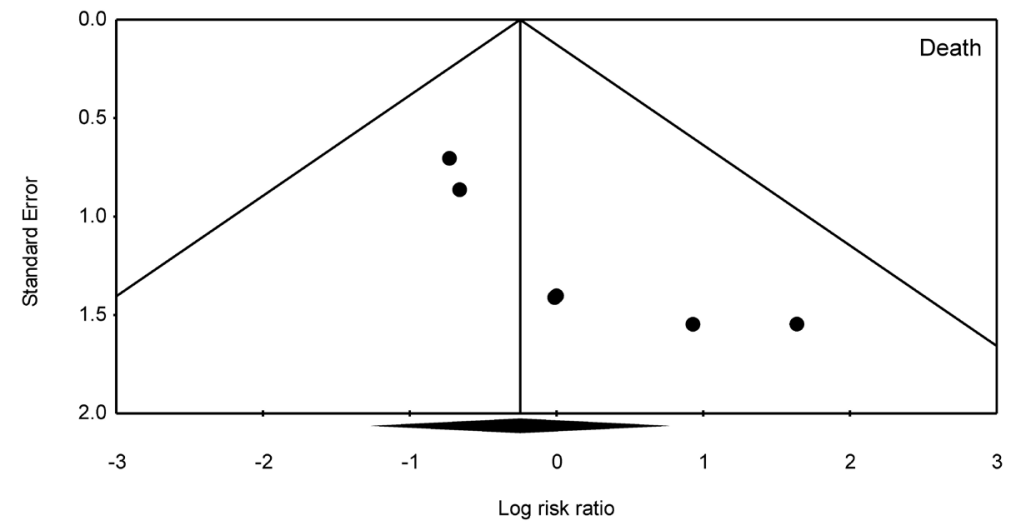

Begg and Mazumdar's test (P-value): 0.060 Egger's test (P-value): 0.020
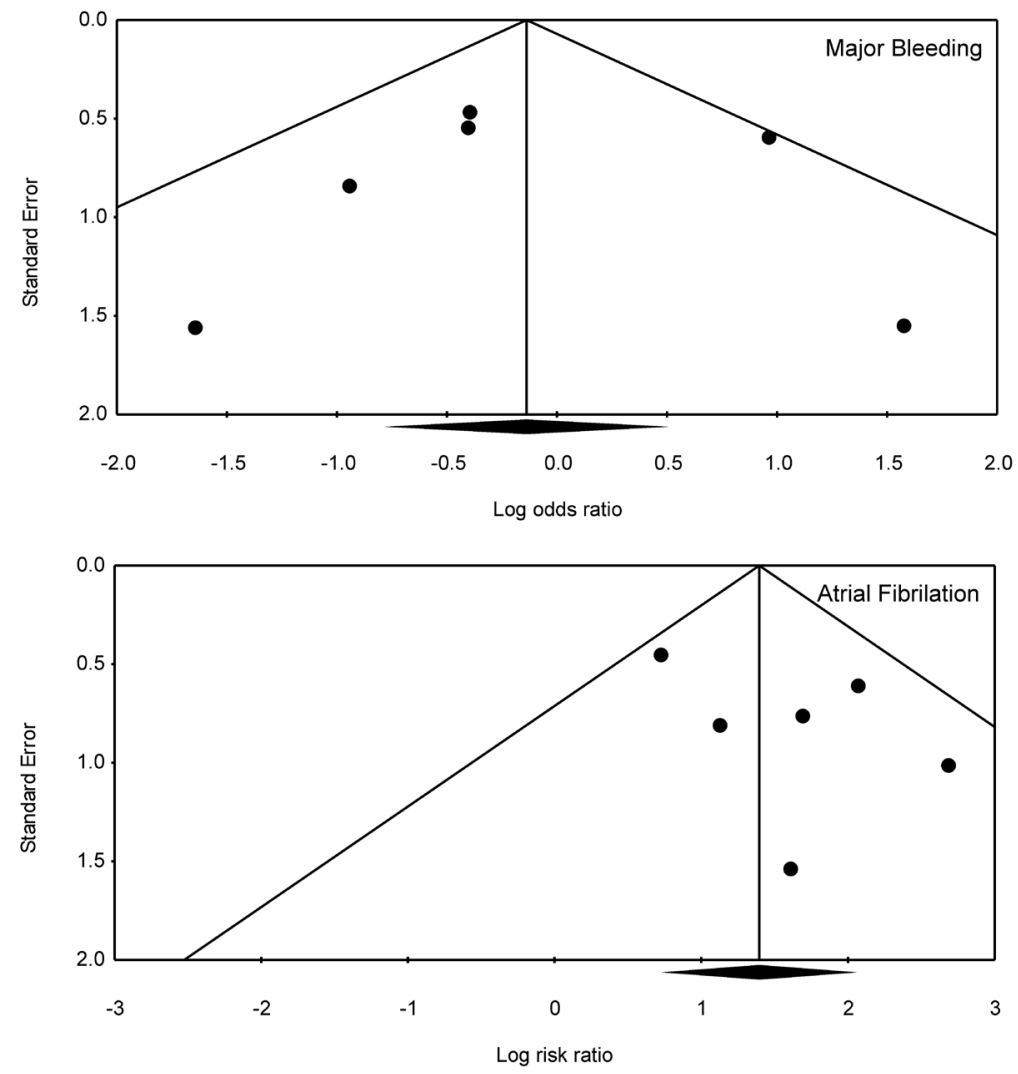

Begg and Mazumdar's test (P-value): 0.573 Egger's test (P-value): 0.707

Fig. 4 - Publication Bias Analysis of Clinical Outcomes by Funnel Plot Graphic. 
A) Stroke - Patients with Atrial Septal Aneurysm

Study name

DEFENSE-PFO 2018

CLOSE 2017

RESPECT 2013

PCT 2013

CLOSURE | 2012

Overall effect

Total ( $95 \% \mathrm{Cl}$ ): 464 (Device Closure); 462 (Medical Therapy)

Total events: 13 (Device Closure); 33 (Medical Therapy)

Test for heterogeneity: $\mathrm{Chi}^{2}=8.48 ; \mathrm{df}=4(\mathrm{P}=0.075) ; \mathrm{I}^{2}=52.8 \%$

Test for overall random effect: $Z=-1.43(P=0.154)$

\author{
Weight (Random) \\ Relative \\ weight \\ $(\%)$
}

$\begin{array}{lllll}0.167 & 0.011 & 2.563 & 0.199 & 12.02\end{array}$

$\begin{array}{lllll}0.048 & 0.003 & 0.813 & 0.035 & 11.46\end{array}$

$\begin{array}{lllll}0.209 & 0.046 & 0.952 & 0.043 & 23.42\end{array}$

$\begin{array}{lllll}2.170 & 0.417 & 11.306 & 0.358 & 21.74\end{array}$

$\begin{array}{lllll}0.824 & 0.315 & 2.158 & 0.694 & 31.36\end{array}$

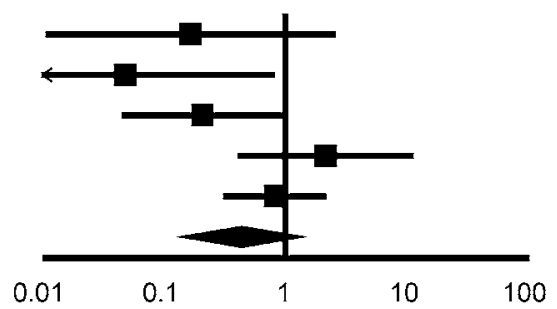

Favours Device Closure Favours Medical Therapy

B) Stroke - Patients without Atrial Septal Aneurysm

\begin{tabular}{|c|c|c|c|c|c|}
\hline \multirow[t]{2}{*}{ Study name } & \multicolumn{4}{|c|}{ Statistics for each study } & Weight (Random) \\
\hline & $\begin{array}{c}\text { Odds } \\
\text { ratio }\end{array}$ & $\begin{array}{l}\text { Lower } \\
\text { limit }\end{array}$ & $\begin{array}{l}\text { Upper } \\
\text { limit }\end{array}$ & P-Value & $\begin{array}{c}\text { Relative } \\
\text { weight }\end{array}$ \\
\hline DEFENSE-PFO 2018 & 0.309 & 0.012 & 7.765 & 0.475 & 2.85 \\
\hline CLOSE 2017 & 0.090 & 0.005 & 1.647 & 0.105 & 3.51 \\
\hline RESPECT 2013 & 0.978 & 0.339 & 2.820 & 0.967 & 24.70 \\
\hline PCT 2013 & 0.325 & 0.086 & 1.223 & 0.096 & 16.19 \\
\hline CLOSURE I 2012 & 0.869 & 0.435 & 1.735 & 0.690 & 52.75 \\
\hline Overall effect & 0.684 & 0.396 & 1.181 & 0.173 & \\
\hline \multicolumn{6}{|c|}{$\begin{array}{l}\text { Total ( } 95 \% \mathrm{Cl} \text { ): } 937 \text { (Device Closure); } 975 \text { (Medical Therapy) } \\
\text { Total events: } 25 \text { (Device Closure); } 42 \text { (Medical Therapy) } \\
\text { Test for heterogeneity: } \text { Chi }^{2}=4.20 ; \mathrm{df}=4(\mathrm{P}=0.379) ;\left.\right|^{2}=4.8 \% \\
\text { Test for overall random effect: } Z=-1.36(P=0.173)\end{array}$} \\
\hline
\end{tabular}

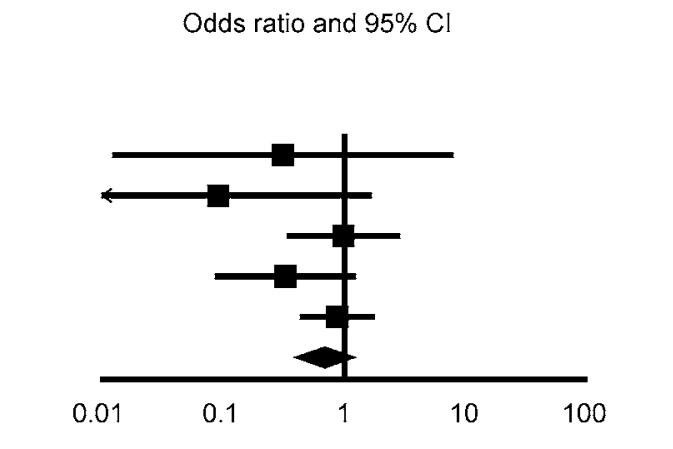

Favours Device Closure

Favours Medical Therapy

Fig. 5 - Sensitivity analysis for the presence of an atrial septal aneurysm.

patients with atrial septal aneurysm, the higher the risk for stroke (Figures 6A, 6B). Conversely, the larger the proportion of effective closure, the lower the risk of stroke (Figure 6C).

\section{DISCUSSION}

\section{Summary of Evidence}

To our knowledge, this is the largest meta-analysis of studies performed to date that provides incremental value by demonstrating that patients seem to benefit from device closures in comparison to medical therapy in the reduction of the rate of stroke. On the other hand, there was an increase in the rates of atrial fibrillation. We did not identify the group of patients with an atrial septal aneurysm as a particular group that benefits from the device closure in the sensitivity analysis, although we identified this variable as a modulation factor of the risk for stroke in the meta-regression. We also observed that the benefit of the device closure in the reduction of the rates of stroke hinges on the rate of effective closure. We did not find evidence that the publication of the DEFENSE-PFO trial changed the scenario in the medical literature.

\section{Some Comments}

The lack of efficacy observed in the CLOSURE I trial has been put down to ineffective PFO closure in the device arm, with $14 \%$ demonstrating significant residual right-to-left shunting, whereas, in the other trials, we observed the following rates: 3.3\% (DEFENSE-PFO), 7\% (CLOSE), 5.5\% (REDUCE), 6.5\% (RESPECT) and 6.5\% (PC trial). Our meta-regression showed that the more successful the closure, the lower the risk of stroke in the device group (Figure 6C). Therefore, we must bare in mind that "procedural success", which was defined in the studies as successful implantation with no complications, does not mean "success of PFO closure", which was defined in the studies as minimal or no shunt after the procedure.

\section{Risk of Bias and Limitations of the Present Study}

There are inherent limitations with meta-analyses, including the use of cumulative data from summary estimates. Patient data were gathered from published data, not from individual patient follow-up. Access to individual patient data would have enabled 


\section{Regression on Log risk ratio}

A)

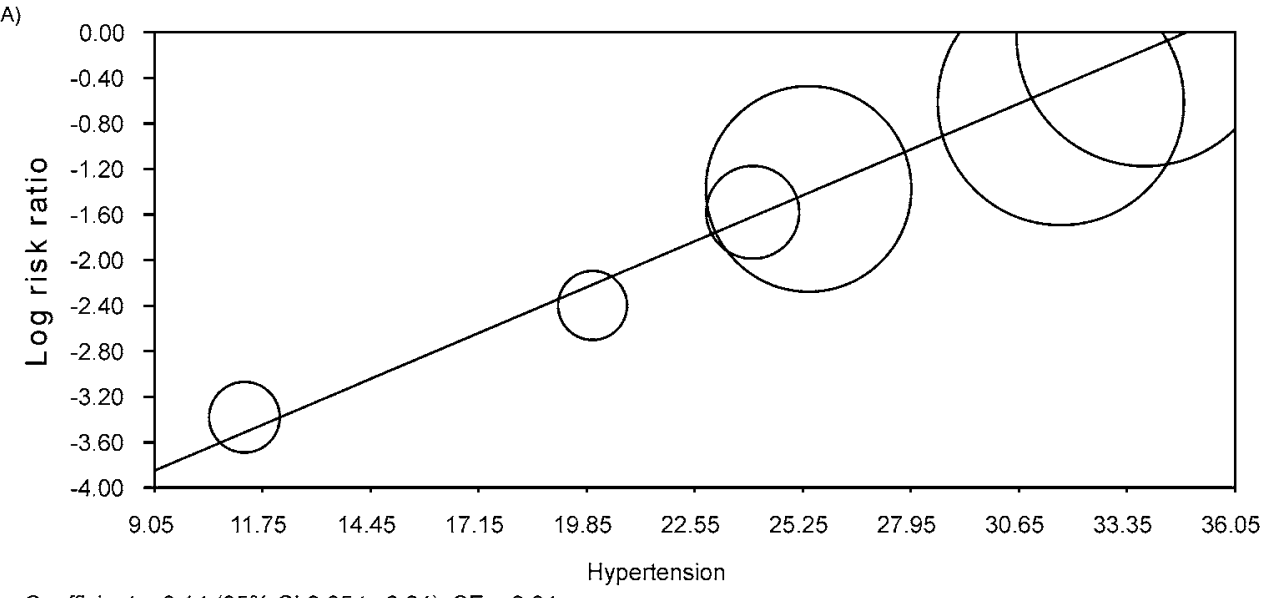

Coefficient $=0.14(95 \% \mathrm{Cl} 0.05$ to 0.24$), \mathrm{SE}=0.04$

$Z=3.14(P$-value $=0.001)$

B)

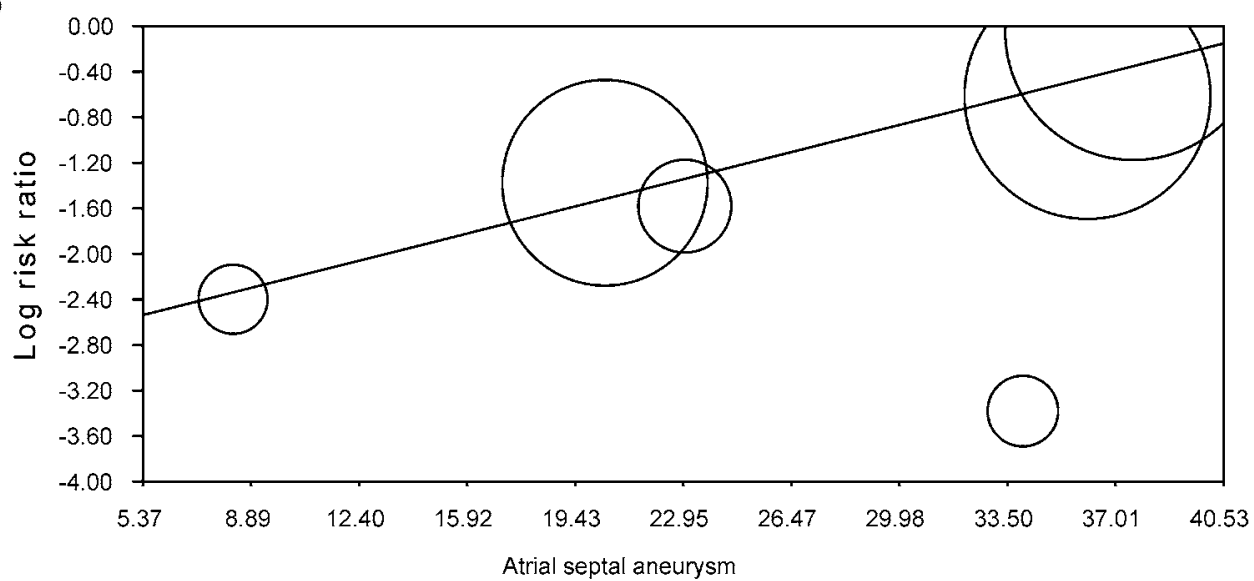

Coefficient $=0.07(95 \% \mathrm{Cl} 0.01$ to 0.12$), \mathrm{SE}=0.03$

$Z=2.33(P$-value $=0.019)$

C)

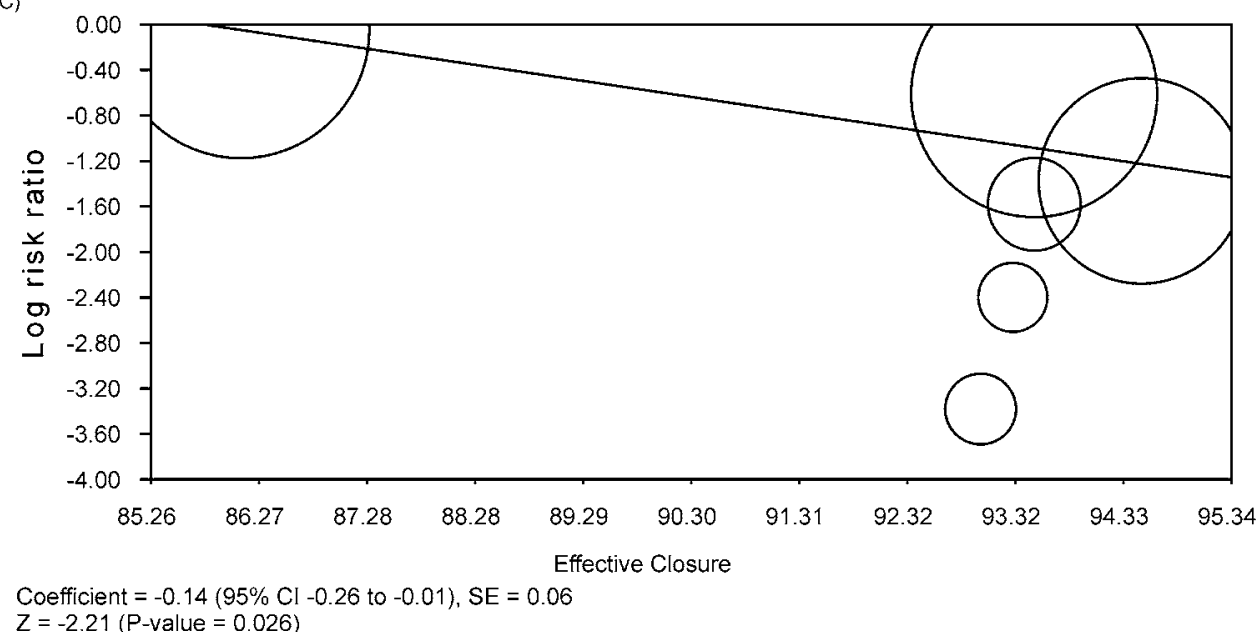

Fig. 6 - Meta-regression analysis. 
us to conduct further subgroup analysis and propensity analysis to account for differences between the treatment groups. This meta-analysis included only data from randomized studies, which do not reflect the "real world" but, on the other hand, are less limited by publication bias, treatment bias, confounders, and a certain tendency to overestimate treatment effects observed in the observational studies, since patient selection alters outcome and thus makes non-randomized studies less robust.

Moreover, besides statitiscal heterogeneity in some analyses, there is also the issue of the clinical heterogeneity that might have played some role in the pooled results. For instance, in the CLOSE trial, eleven different devices were appplied for PFO closure. In the antiplatelet-only group and the PFO closure

\section{Authors' roles \& responsibilities}

MPBOS Conception and design, analysis and interpretation of data, drafting of the manuscript, revising it critically for important intellectual content; final approval of the version to be published

EESV Collection of data, drafting of the manuscript, revising it critically for important intellectual content; final approval of the version to be published

LRPC Collection of data, drafting of the manuscript, revising it critically for important intellectual content; final approval of the version to be published

RGSD Revising it critically for important intellectual content; final approval of the version to be published

SCR Revising it critically for important intellectual content; final approval of the version to be published

AMM Revising it critically for important intellectual content; final approval of the version to be published

RFAL Revising it critically for important intellectual content; final approval of the version to be published

$\mathrm{RCL} \quad$ Revising it critically for important intellectual content; final approval of the version to be published

\section{REFERENCES}

1. Kernan WN, Ovbiagele B, Black HR, Bravata DM, Chimowitz MI, Ezekowitz MD, et al; American Heart Association Stroke Council, Council on Cardiovascular and Stroke Nursing, Council on Clinical Cardiology, and Council on Peripheral Vascular Disease. Guidelines for the prevention of stroke in patients with stroke and transient ischemic attack: a guideline for healthcare professionals from the American Heart Association/ American Stroke Association. Stroke. 2014;45(7):2160-236.

2. Ando T, Holmes AA, Pahuja M, Javed A, Briasoulis A, Telila T, et al. Metaanalysis comparing patent foramen ovale closure versus medical therapy to prevent recurrent cryptogenic stroke. Am J Cardiol. 2018;121(5):649-55.

3. De Rosa S, Sievert H, Sabatino J, Polimeni A, Sorrentino S, Indolfi C. Percutaneous closure versus medical treatment in stroke patients with patent foramen ovale: a systematic review and meta-analysis. Ann Intern Med. 2018;168(5):343-50. group, 410 patients (86.7\%) received aspirin, 51 (10.8\%) received clopidogrel, $6(1.3 \%)$ received aspirin with extended-release dipyridamole, and $6(1.3 \%)$ received aspirin with clopidogrel. As we can see, not all of patients were $100 \%$ equally treated.

\section{CONCLUSION}

This meta-analysis found that stroke rates are lower with percutaneously implanted device closure than with medical therapy alone, being these rates modulated by the rates of effective closure. The publication of the DEFENSE-PFO trial did not change the current scenario.
4. Shah R, Nayyar M, Jovin IS, Rashid A, Bondy BR, Fan TM, et al. Device closure versus medical therapy alone for patent foramen ovale in patients with cryptogenic stroke: a systematic review and meta-analysis. Ann Intern Med. 2018;168(5):335-42.

5. Ntaios G, Papavasileiou V, Sagris D, Makaritsis K, Vemmos K, Steiner T, et al. Closure of patent foramen ovale versus medical therapy in patients with cryptogenic stroke or transient ischemic attack: updated systematic review and meta-analysis. Stroke. 2018;49(2):412-8.

6. Sá MPBO, Oliveira Neto LAP, Nascimento GCSD, Vieira EEDS, Martins GL, Rodrigues KC, et al. Closure of patent foramen ovale versus medical therapy after cryptogenic stroke: meta-analysis of five randomized controlled trials with 3440 patients. Braz J Cardiovasc Surg. 2018;33(1):89-98.

7. Riaz H, Khan MS, Schenone AL, Waheed AA, Khan AR, Krasuski RA. Transcatheter closure of patent foramen ovale following cryptogenic stroke: an updated meta-analysis of randomized controlled trials. Am Heart J. 2018;199:44-50.

8. Abdelaziz HK, Saad M, Abuomara HZ, Nairooz R, Pothineni NVK, Madmani $M E$, et al. Long-term outcomes of patent foramen ovale closure or medical therapy after cryptogenic stroke: a meta-analysis of randomized trials. Catheter Cardiovasc Interv. 2018. doi: 10.1002/ccd.27636.

9. Smer A, Salih M, Mahfood Haddad T, Guddeti R, Saadi A, Saurav A, et al. Meta-analysis of randomized controlled trials on patent foramen ovale closure versus medical therapy for secondary prevention of cryptogenic stroke. Am J Cardiol. 2018;121(11):1393-9.

10. Akobeng AK, Abdelgadir I, Boudjemline Y, Hijazi ZM. Patent foramen ovale (PFO) closure versus medical therapy for prevention of recurrent stroke in patients with prior cryptogenic stroke: a systematic review and meta-analysis of randomized controlled trials. Catheter Cardiovasc Interv. 2018. doi: 10.1002/ccd.27615.

11. Ahmad Y, Howard JP, Arnold A, Shin MS, Cook C, Petraco R, et al. Patent foramen ovale closure vs. medical therapy for cryptogenic stroke: a meta-analysis of randomized controlled trials. Eur Heart J. 2018;39(18):1638-49.

12. Piccolo R, Franzone A, Siontis GCM, Stortecky S, Pilgrim T, Meier B, et al. Patent foramen ovale closure vs. medical therapy for recurrent stroke prevention: Evolution of treatment effect during follow-up. Int J Cardiol. 2018;255:29-31.

13. Moher D, Liberati A, Tetzlaff J, Altman DG; PRISMA Group. Preferred reporting items for systematic reviews and meta-analyses: the PRISMA statement. Ann Intern Med. 2009;151(4):264-9.

14. Higgins JP, Thompson SG, Deeks JJ, Altman DG. Measuring inconsistency in meta-analyses. BMJ. 2003;327(7414):557-60.

15. DerSimonian R, Kacker R. Random-effects model for meta-analysis of clinical trials: an update. Contemp Clin Trials. 2007;28(2):105-14.

16. Begg CB, Mazumdar M. Operating characteristics of a rank correlation 
test for publication bias. Biometrics. 1994;50(4):1088-101.

17. Egger M, Davey Smith G, Schneider M, Minder C. Bias in meta-analysis detected by a simple, graphical test. BMJ. 1997;315(7109):629-34.

18. Lee PH, Song JK, Kim JS, Heo R, Lee S, Kim DH, et al. Cryptogenic stroke and high-risk patent foramen ovale: the DEFENSE-PFO trial. J Am Coll Cardiol. 2018;71(20):2335-42.

19. Mas JL, Derumeaux G, Guillon B, Massardier E, Hosseini H, Mechtouff L, et al; CLOSE investigators. Patent foramen ovale closure or anticoagulation vs. antiplatelets after stroke. N Engl J Med. 2017;377(11):1011-21.

20. Søndergaard L, Kasner SE, Rhodes JF, Andersen G, Iversen HK, NielsenKudsk JE, et al; Gore REDUCE Clinical Study Investigators. Patent foramen ovale closure or antiplatelet therapy for cryptogenic stroke. N Engl J Med. 2017;377(11):1033-42.

21. Carroll JD, Saver JL, Thaler DE, Smalling RW, Berry S, MacDonald LA, et al; RESPECT Investigators. Closure of patent foramen ovale versus medical therapy after cryptogenic stroke. N Engl J Med. 2013;368(12):1092-100. 22. Meier B, Kalesan B, Mattle HP, Khattab AA, Hildick-Smith D, Dudek D, et al; PC Trial Investigators. Percutaneous closure of patent foramen ovale in cryptogenic embolism. N Engl J Med. 2013;368(12):1083-91.

23. Furlan AJ, Reisman M, Massaro J, Mauri L, Adams H, Albers GW, et al; CLOSURE I Investigators. Closure or medical therapy for cryptogenic stroke with patent foramen ovale. N Engl J Med. 2012;366(11):991-9. 